\title{
A Prospective Randomised Open Label Study to Evaluate the Response Rate and Toxicity of Gefitinib in the Treatment of Carcinoma Cervix Patients on Chemoradiotherapy
}

\author{
Sowmya MS', Manjunath², Basavanna $\mathrm{PL}^{3}$, Ramya KN4, Mukesh ${ }^{5, *}$ \\ ${ }^{1}$ Senior Resident, Department of Pharmacology, MMC\&RI, Mysore, Karnataka, INDIA. \\ ${ }^{2}$ Assistant Professor, Department of General Surgery, MMC\&RI, Mysore, Karnataka, INDIA. \\ ${ }^{3}$ Professor and HOD, Department of Clinical Pharmacology, MMC\&RI, Mysore, Karnataka, INDIA. \\ ${ }^{4}$ Drug Safety Physician, Bioclinica MNC, Mysore, Karnataka, INDIA. \\ ${ }^{5}$ Assistant Professor, Department of Radiotherapy, MMC\&RI, Mysore, Karnataka, INDIA.
}

\begin{abstract}
Introduction: Cervical cancer, on a global forum stands third most commonly diagnosed cancer. It is the fourth leading cause of cancer death in women. Despite with treatment of surgery, radiation and or chemotherapy, cervical cancer may persist or recur months or years after completion of initial treatment. Recently, the epidermal growth factor receptor (EGFR; HER1/erbB1) has been recognized as target for cancer therapy in numerous cancers. Clinical trials have demonstrated that only a subset of patients respond to EGFR inhibitors. Therefore the present study aimed to study the response rate of the drug gefitinib in patients receiving cisplatin-based chemotherapy in cervical cancer. Methods: study was a randomized prospective study. Patients were randomized into two arms in the ratio $2: 1$ to get a statistically significant result. The sample size (n) was 16 in the experiment arm (Gefitinib+ Cisplatin) and 32 in the control (Cisplatin) arm. Toxicity and Response rate was assessed during the treatment, one month and 3 months post treatment. Results: A total of 23 subjects were included in the final analysis. On cisplatin were $16(69.6 \%)$ and on Cisplatin+Gefitinib were 7 (30.4\%). Our study attempted to evaluate the response rate and safety of gefitinib drug on locally advance cervical cancerous growth among 16 subjects, but because of the toxicity we couldn't complete the study. Gefitinib was found to cause severe adverse drug reactions like grade 3 diarrhoea, fall in haemoglobin in many patients. Response rate was found to be satisfactory in both the arms. Conclusion: Due to overall small sample size, patients lost during treatment and unequal sample among the cisplatin and cisplatin +gefitinib group the analysis of disease-free period, adverse events could not be analysed. The efficacy of gefitinib among cervical patients was inconclusive and warrants further research in future.
\end{abstract}

Key words: Cervical cancer, Toxicity, Gefitinib, Cisplatin, EGFR inhibitor.

\section{INTRODUCTION}

Cancer by definition, is a disease caused by an uncontrolled division of abnormal cells in a part of the body.

\begin{tabular}{|l|c|}
\hline \multicolumn{2}{|c|}{ Access this article online } \\
\hline $\begin{array}{l}\text { Website: } \\
\text { www.jcramonline.com }\end{array}$ & Quick Response code \\
\hline DOI: & \\
10.5530/jcram.1.2.14 & \\
& \\
\hline
\end{tabular}

Cancer is the second most common disease in India, responsible for maximum mortality. The government has laid down 4 priority cancers- breast, cervical, oral and lung cancer, which constitute $41 \%$ cancer burden, the report mentioned. ${ }^{1}$

Cervical cancer, on a global forum, stands third most commonly diagnosed cancer. It is the fourth leading cause of cancer death in women. ${ }^{1}$ According to the reports of GLOBOCON 2018, about $9 \%$ of new cases of cervical cancer contribute to a total percentage of cancer among women and $8 \%$ to all cancer deaths. ${ }^{2}$ 
The most targeted population to Cervical cancer are the developing and underdeveloped countries. Hence, around $83 \%$ of cervical cancer cases are contributed by developing countries. The incidence of cervical cancers among the developed countries has declined over a decade due to adequate health resources and effective screening programs. ${ }^{3}$ Each year in India, a total of 122,844 women are diagnosed with cervical cancer, and 67,477 dies from the disease. ${ }^{4}$ Several risk factors contribute to cause cervical cancer. These include sexual intercourse at an early age, multiple sexual partners, tobacco smoking, long-term oral contraceptive use, low socioeconomic status, immunosuppressive therapy, and micronutrient deficiency. ${ }^{5} \mathrm{~A}$ strong association of oncogenic human papillomavirus (HPV) in the development of cervical cancer has been established over the years. ${ }^{6}$

Cervical cancer is clinically staged according to the International Federation of Gynecology and Obstetrics (FIGO) guidelines. A meta-analysis, ${ }^{5}$ evaluated the efficiency of surgical, radiotherapy and chemotherapy in treating cervical cancers. This analysis found surgical treatment efficient with overall and disease-free survival in initial stages of cervical cancer.

Chemoradiotherapy showed improved survival compared with radiotherapy in women with bulky early-stage cervical cancer. ${ }^{11}$ Combined chemoradiotherapy improves overall and progression-free survival when used either before or after hysterectomy. ${ }^{7}$ Despite with treatment of surgery, radiation and or chemotherapy, cervical cancer may persist or recur months or years after completion of initial treatment. ${ }^{8}$ Recently, the epidermal growth factor receptor (EGFR; HER1/erbB-1) has been recognized as a target for cancer therapy in numerous cancers. EGFR is a transmembrane glycoprotein receptor, is activated by an endogenous ligand binding with receptor homo- or heterodimerization and autophosphorylation of the intracellular tyrosine kinase domain. ${ }^{9}$

Increased EGFR expression by various malignancies has correlated to poor prognosis and resistance to treatment in many tumour entities, including cervical carcinoma. ${ }^{10}$

The overexpression of EGFR is thought to be negatively associated with survival in cervical cancer patients, and the relationship between EGFR overexpression and altered survival in patients with cervical cancer has, therefore been studied for many years. Therefore, the present study aimed to study the response rate of the drug gefitinib in patients receiving cisplatin-based chemotherapy in cervical cancer.

\section{MATERIALS AND METHODS}

Study site: This study was conducted in the Department of oncology at MMC\&RI, Mysore. Study population: Female patients aged $>18$ years diagnosed as carcinoma cervix receiving chemoradiation with cisplatin $40 \mathrm{mg} / \mathrm{m} 2$ and radiation of $50 \mathrm{~Gy} / 25$ fraction were selected based on inclusion and exclusion criteria and randomized into two groups, group A and group B.

Study design: The current study was a randomized prospective study.

Sampling method: All the eligible subjects were recruited into the study consecutively by convenient sampling till the sample size is reached.

Study duration: The data collection for the study was done between Nov 2017 to March 2019 for a period of 15 months.

Inclusion Criteria: 1). Female aged >18yrs. 2) FIGO stage II to stage III cervical cancer. 3)Histopathologically proven cervical cancer. 4 . Serum creatinine $<1.4 \mathrm{mg} / \mathrm{dl}$.

Exclusion criteria: 1) Pregnancy 2) HIV and Immunocompromised 3) Any allergy to gefitinib or cisplatin 4) Surgery for cervical cancer 5) Renal failure 6) Breast feeding mother.

Ethical considerations: Study was approved by institutional human ethics committee. Informed written consent was obtained from all the study participants

Methodology: Patients were randomized into two arms in the ratio 2:1 to get a statistically significant result. Control arm had received concurrent chemoradiation. The dose of radiation is $50 \mathrm{~Gy} / 25$ fraction, along with cisplatin with HDR Brachytherapy $40 \mathrm{mg} / \mathrm{m} 2$ weekly for 5 cycles. The experiment arm had received the same treatment as above plus tab gefitinib $250 \mathrm{mg}$ starting one week prior to chemoradiation and continued throughout external radiation. Patients were determined for toxicity and graded. Complete blood counts, renal function tests, liver function tests were done weekly before each cycle of chemotherapy. Toxicity was determined during the treatment, one month and 3 months post-treatment. If patients develop Grade 3 or Grade 4 Toxicity, then treatment was stopped until the patient recovers from symptoms completely. MRI/ CT abdomen and pelvis was done before starting treatment and then one month and 3 months post-treatment.

It was planned to allocate 16 participants to the intervention are (Cisplatin + gefitinib) and 32 participants to control arm (Cisplatin alone). But due to the high incidence of Diarrhea of grade II and grade IV in the intervention arm, the trial was prematurely terminated. At the time of termination of the trail, a total of 7 
participants were randomized and received the intervention in cisplatin + gefitinib group and 16 participants have received cisplatin alone. Hence the final analysis included a total of 23 participants with 7 subjects in the intervention arm and 16 subjects in the control arm.

\section{RESULTS}

A total of 23 subjects were included in the final analysis. Descriptive analysis of drug/study group in the study population $(n=23)$

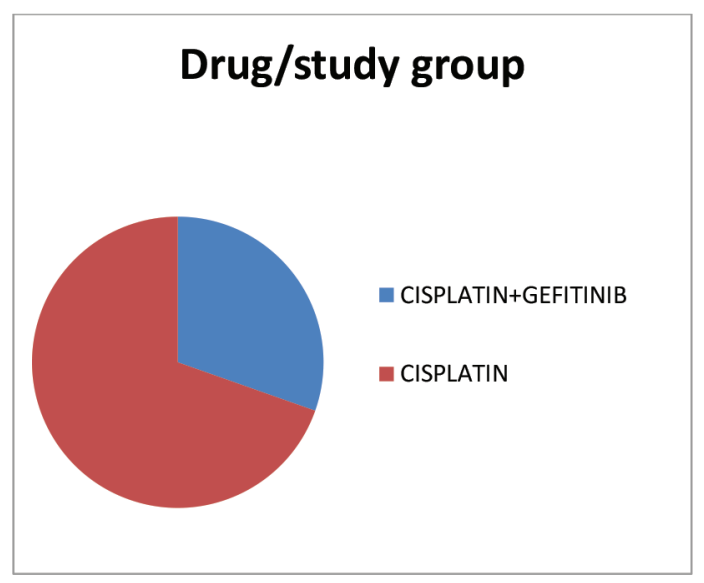

Comparison of complete response between drug $(n=23)$

\begin{tabular}{ccccc}
\hline $\begin{array}{c}\text { Complete } \\
\text { Response }\end{array}$ & $\begin{array}{c}\text { Cisplatin } \\
(\boldsymbol{n}=16)\end{array}$ & $\begin{array}{c}\text { Cisplatin+ } \\
\text { Gefitinib } \\
(\boldsymbol{n}=7)\end{array}$ & $\begin{array}{c}\text { Chi } \\
\text { square }\end{array}$ & $\begin{array}{c}\text { Fisher } \\
\text { exact } \\
\boldsymbol{P} \text { value }\end{array}$ \\
\hline YES & $\begin{array}{c}11 \\
\text { NO }\end{array}$ & $5(71.43 \%)$ & & \\
& $(68.75 \%)$ & & 0.017 & 1.000 \\
\cline { 1 - 2 } & $5(31.25 \%)$ & $2(28.57 \%)$ & & \\
\cline { 1 - 2 }
\end{tabular}

Comparison of partial response between drug $(n=23)$

\begin{tabular}{ccc}
\hline Partial Response & Cisplatin $(\mathbf{n}=16)$ & $\begin{array}{c}\text { Cisplatin + Gefitinib } \\
(\mathbf{n}=7)\end{array}$ \\
\hline YES & $4(25 \%)$ & $0(0 \%)$ \\
NO & $12(75 \%)$ & $7(100 \%)$ \\
\hline
\end{tabular}

*No statistical test was applied- due to o subjects in the cells

Comparison of no response between drug $(n=23)$

\begin{tabular}{ccccc}
\hline $\begin{array}{c}\text { No } \\
\text { Response }\end{array}$ & $\begin{array}{c}\text { Cisplatin+ } \\
\text { Gefitinib }\end{array}$ & Cisplatin & $\begin{array}{c}\text { Chi } \\
\text { square }\end{array}$ & $\boldsymbol{P}$ value \\
\hline No & $7(50 \%)$ & $16(50 \%)$ & 0.000 & 1.000 \\
\hline
\end{tabular}

\section{Grading of diarrhea:}

\begin{tabular}{ccccccc}
\hline Cisplatin Week 1 & Week 2 & Week 3 & Week 4 & Week 5 & 1 & Month 3 Month \\
\hline Grade & Grade 1 & Grade 2 & Grade 2 & Grade 2 & Grade 2 \\
& \multicolumn{1}{c}{-} \\
$(6.3 \%)$ & $(62.5 \%)$ & $(56.3 \%)$ & $(62.5 \%)$ & $(56.3 \%)$ \\
\hline
\end{tabular}

\section{Gefitinib group $(n=7)$}

\begin{tabular}{|c|c|c|c|c|c|c|c|}
\hline Grade & Grade 2 & Grade 3 & Grade 3 & Grade 3 & Grade 3 & & \\
\hline & $\begin{array}{c}6 \\
(85.7 \%)\end{array}$ & $\begin{array}{c}6 \\
(85.7 \%)\end{array}$ & $\begin{array}{c}6 \\
(85.7 \%)\end{array}$ & $\begin{array}{c}2 \\
(28.6 \%)\end{array}$ & $\begin{array}{c}4 \\
(57.1 \%)\end{array}$ & - & - \\
\hline
\end{tabular}

\section{DISCUSSION}

Total subjects A total of 23 subjects were included in the final analysis. On cisplatin were $16(69.6 \%)$ and on Cisplatin + Gefitinib were 7 (30.4\%). The mean hemoglobin in patients on cisplatin was $11.22 \pm 2.43$ and on Cisplatin + Gefitinib was $9.99 \pm 2.38$. The mean urea was $25.71 \pm 8.95$ in cisplatin used patients, and it was $20.71 \pm 3.55$ Cisplatin + Gefitinib used patients. The mean creatinine was $0.83 \pm 0.27$ in cisplatin used patients, and it was $0.69 \pm 0.15$ Cisplatin + Gefitinib used patients. The difference in the lab parameters in 1 week between drug was statistically not significant $(P$ value $>0.05)$. In the cisplatin group, $16(100 \%)$ were with nausea, $7(43.75 \%)$ were with vomiting, and $7(43.75 \%)$ were with diarrhea. In cisplatin + gefitinib, $6(85.71 \%)$ were with nausea, $6(85.71 \%)$ were with vomiting, and $7(100 \%)$ were with diarrhea. The difference in the proportion of chief complaints in week 2 between drug was statistically not significant ( $P$ value $>0.05)$.

Till date, Cisplatin has been the choice of drug in treating patients with an advanced stage of cervical carcinoma undergoing radiotherapy as well. Although cisplatin is the 66 drug of choice in treating these patients, its standard drug dosage has not been recognized. Targeted therapies are the most effective and popular treatment among various cancers. The epidermal growth factor receptor expressed by many cancerous growths such as head and neck, colorectal, on-small cell lung cancers including cervical cancer, has been identified as a potent anti-cancer target. One such drug which inhibits the EGFR 67 was identified as Gefitinib and had shown its efficiency in treating various tumors which expresses EGFR. ${ }^{11}$

In our study the gefitinib therapy was given for one month and among the Cisplatin+ Gefitinib group, in Week 1 the proportion of Grade 3 people was $6(85.7 \%)$, in week 2 the proportion of grade 3 was $6(85.7 \%)$, in week 3 the proportion of grade 3 was $6(85.7 \%)$, in week 4 the proportion of grade 3 was $2(28.6 \%)$, and in week 5 the 68 proportion of grade 3 was 4 (57.1\%). While among the cisplatin group, in Week 1 the proportion of Grade 1 people was 1(6.3\%), in week 2 the proportion of grade 2 was $10(62.5 \%)$, 
in week 3 the proportion of grade 2 was 9 (56.3\%), in week 4 the proportion of grade 2 was $10(62.5 \%)$, and in week 5 the proportion of grade 2 was $9(56.3 \%)$. In the Cisplatin group, 11 (68.75\%) were given a complete response.

Although our study showed no statistically significant results between the two groups, the mean creatine and symptoms of nausea and diarrhea was much lesser in cisplatin + gefitinib group compared to the cisplatin group. The present study results of gefitinib efficacy and safety was inconclusive due to small sample size, non-uniformity of patients among the group and few patients among the groups were lost during the course of the treatment. Hence further study with large sample size should be considered to evaluate the efficacy of gefitinib in cervical cancer patients.

\section{CONCLUSION}

Gefitinib trial among cervical cancer patients has been studied least, and among these few studies, the trials were conducted on recurrent and metastatic cervical cancer patients showing varied results. Our study also attempted to evaluate the response rate and safety of gefitinib drug on locally advance cervical cancerous growth among 16 subjects, but because of the toxicity, we couldn't complete the study. However, the lab parameters, chief complaints between groups showed statistical insignificant results. Thus, the efficacy of gefitinib among cervical patients was inconclusive and warrants further research in future.

\section{Limitations}

Due to the overall small sample size, patients lost during treatment and unequal sample among the cisplatin and cisplatin +gefitinib group, the analysis of the diseasefree period, adverse events could not be analyzed. The drug dose of Gefitinib was not established or mentioned.

\section{Recommendation}

Randomized control trial of gefitinib among cervical cancer patients with large sample size is recommended as the previous few studies have shown varied results.
These studies with a small sample and their varied results warrant further research.

\section{Funding}

The author(s) received no financial support for the research, authorship, and/or publication of this article.

\section{CONFLICT OF INTEREST}

The author(s) declared no potential conflicts of interest with respect to the research, authorship, and/or publication of this article

\section{REFERENCES}

1. Jemal A, Bray F, Center MM, Ferlay J, Ward E, Forman D. Global cancer statistics. CA Cancer J Clin. 2011;61(2):69-90. doi: 10.3322/caac.20107, PMID 21296855.

2. Bray F, Ferlay J, Soerjomataram I, Siegel RL, Torre LA, Jemal A. Global cancer statistics 2018: GLOBOCAN estimates of incidence and mortality worldwide for 36 cancers in 185 countries. CA Cancer J Clin. 2018;68(6):394-424. doi: 10.3322/caac.21492, PMID 30207593.

3. Saslow D, Solomon D, Lawson HW, Killackey M, Kulasingam SL, Cain J, et al. CA Cancer J Clin. 2012;62(3):147-72. doi: 10.3322/caac.21139, PMID 22422631.

4. Sreedevi A, Javed R, Dinesh A. Epidemiology of cervical cancer with special focus on India. Int J Womens Health. 2015;7:405-14. doi: 10.2147/IJWH. S50001, PMID 25931830.

5. Martin-Hirsch PL, Wood NJ. Cervical cancer. BMJ Clin Evid. 2011;2011:pii 0818. PMID 21791123.

6. Li N, Franceschi S, Howell-Jones R, Snijders PJ, Clifford GM. Human papillomavirus type distribution in 30,848 invasive cervical cancers worldwide: variation by geographical region, histological type and year of publication. Int J Cancer. 2011;128(4):927-35. doi: 10.1002/ijc.25396, PMID 20473886.

7. Peters WA, Liu PY, Barrett RJ, Stock RJ, Monk BJ, Berek JS, et al. Concurrent chemotherapy and pelvic radiation therapy compared with pelvic radiation therapy alone as adjuvant therapy after radical surgery in high-risk earlystage cancer of the cervix. J Clin Oncol. 2000;18(8):1606-13. doi: 10.1200/ JCO.2000.18.8.1606, PMID 10764420.

8. National cancer Institute. Cervical cancer treatment $(P D Q \Re)-$ health professional version [internet]. National cancer Institute; 2019; [cited Nov 15 2019].

9. Schlessinger J. Ligand-induced, receptor-mediated dimerization and activation of EGF receptor. Cell. 2002;110(6):669-72. doi: 10.1016/s00928674(02)00966-2, PMID 12297041.

10. Corvò R, Antognoni P, Sanguineti G. Biological predictors of response to radiotherapy in head and neck cancer: recent advances and emerging perspectives. Tumori. 2001;87(6):355-63. doi: 10.1177/030089160108700601, PMID 11989586.

11. Herbst RS, Fukuoka M, Baselga J. Gefitinib--a novel targeted approach to treating cancer. Nat Rev Cancer. 2004;4(12):956-65. doi: 10.1038/nrc1506, PMID 15573117.

Cite this Article : Sowmya MS, Ramya KN, Manjunath. A Prospective Randomised Open Label Study to Evaluate the Response Rate and Toxicity of Gefitinib in the Treatment of Carcinoma Cervix Patients on Chemoradiotherapy. J Clinical Res and Appl Med. 2021;1(2):59-62. 